\title{
A cost-utility analysis of etanercept for the treatment of moderate-to-severe psoriasis in Italy
}

This article was published in the following Dove Press journal:

ClinicoEconomics and Outcomes Research

14 October 2009

Number of times this article has been viewed

\author{
Giorgio L Colombo' \\ Sergio Di Matteo ${ }^{2}$ \\ Ketty Peris ${ }^{3}$ \\ Maria Concetta Fargnoli ${ }^{3}$ \\ Maria Esposito ${ }^{4}$ \\ Annamaria Mazzotta ${ }^{4}$ \\ Sergio Chimenti ${ }^{4}$ \\ 'Faculty of Pharmacy, University \\ of Pavia, Pavia, Italy; ${ }^{2}$ S.A.V.E. Studi \\ Analisi Valutazioni Economiche, Milan, \\ Italy; ${ }^{3}$ Department of Dermatology, \\ University of L'Aquila, L'Aquila, \\ Italy; ${ }^{4}$ Department of Dermatology, \\ University of Rome Tor Vergata, \\ Rome, Italy
}

Introduction: Biologic therapies have proven efficacious for patients with moderate-to-severe psoriasis. However, their economic value compared with standard of care in Italy has not been explored. This study estimates the cost-effectiveness of intermittent therapy with etanercept in patients with moderate-to-severe plaque-type psoriasis in comparison with nonsystemic therapy in Italy.

Methods: This study employs cost-utility analysis using a Markov model adapted from the British "York model". It compares the cost per quality-adjusted life-year (QALY) of intermittent etanercept (25 mg twice weekly) versus nonsystemic therapy. Data on efficacy and changes in quality of life were derived from three etanercept clinical trials. Direct costs of treating psoriasis patients, including hospitalizations and dermatology clinic visits, were taken from an Italian cost-of-illness study. Extrapolations were made to evaluate the cost-effectiveness of intermittent etanercept versus nonsystemic therapy over a period of ten years.

Results: For the group of patients with moderate and severe plaque psoriasis (initial Psoriasis Area and Severity Index $[$ PASI $\geq 10]$ ) the incremental cost-effectiveness ratio (ICER) for etanercept compared with nonsystemic therapy was $€ 33,216 / \mathrm{QALY}$; for the group of patients with severe psoriasis (PASI $\geq 20$ ), the ICER was $€ 25,486 /$ QALY.

Conclusions: Within the Italian health care system, intermittent etanercept is a cost-effective therapeutic option compared with nonsystemic therapy for the group of patients with moderate and severe plaque psoriasis. For patients with PASI $\geq 20$, cost-effectiveness of etanercept is even greater.

Keywords: cost-utility, cost-effectiveness, psoriasis, etanercept, Markov model

\section{Introduction}

Psoriasis is a common inflammatory skin disorder affecting between $0.5 \%$ and $4.6 \%$ of the world population; the most common form is plaque-type psoriasis occurring in more than $80 \%$ of cases. ${ }^{1}$ Psoriasis is a chronic disease that can be physically and emotionally debilitating and is associated with profoundly impaired quality of life. ${ }^{2}$ Because of its chronic nature, it can require lifelong symptom management.

Treatments available for the relief of moderate-to-severe psoriasis include photochemotherapy (PUVA) and systemic agents such as ciclosporin, methotrexate, and retinoids. Although effective, these therapies are associated with considerable toxicity which limits their long-term use.

In recent years, a better understanding of the immunopathogenesis of psoriasis has led to the development of more targeted biological drugs, capable of neutralizing specific components of the immune system responsible for the inflammatory response.
Correspondence: Giorgio L Colombo Faculty of Pharmacy, University of Pavia, Viale Taramelli, I2, 27I 00 Pavia, Italy $\mathrm{Tel}+390248519230$

Fax +390248198430

Email giorgio.colombo@unipv.it 
So far, the role of the biologics, namely anti-T-cell agents and inhibitors of tumor necrosis factor-alpha (TNF- $\alpha$ ), has been limited given the relative lack of data on long-term efficacy and safety ${ }^{3}$ and also the fact that in terms of drug acquisition they are costlier than conventional therapies. Some of these agents have been evaluated for longer periods recently and their efficacy and safety profiles suggest that they are likely to offer an alternative treatment strategy with the possibility of long-term continuous therapy, which may lead to better disease control and improved quality of life. ${ }^{4}$

Evidence is emerging that psoriasis may be associated with metabolic syndromes including insulin resistance, obesity, dyslipidemia, and hypertension. Consequently patients may be at a higher risk for cardiovascular events. Since the relationship between psoriasis and comorbidities such as metabolic syndrome and cardiovascular disease is likely to be linked to the underlying chronic inflammatory nature of psoriasis, ${ }^{5}$ biological agents may become central to the future clinical management of psoriasis and related comorbidities. A better understanding of the cost-effectiveness of biological agents is thus desirable. At present, three biologic therapies, etanercept (Enbrel), ${ }^{6}$ infliximab (Remicade), ${ }^{7}$ and adalimumab (Humira), ${ }^{8}$ are licensed for the treatment of moderate-to-severe psoriasis in Italy.

In our study we have undertaken a cost-utility analysis of etanercept, a human soluble recombinant TNF receptor protein, indicated, similarly to the other biologic agents, for the treatment of moderate-to-severe psoriasis in adults who failed to respond to, or who have a contraindication to, or are intolerant to other systemic therapy. Data on efficacy and safety of etanercept over 12 and 24 weeks have been demonstrated in phase III clinical trials. ${ }^{9}$ Our aim is to help better delineate the cost-effectiveness of etanercept compared with nonsystemic therapy by extrapolating its efficacy and costs over a 10-year time horizon using a Markov model.

\section{Material and methods Description of the model}

To estimate the longer-term health effects and costs of treatment with intermittent etanercept, a Markov model was developed based on the "York Model" created by the CRD/CHE Technology Assessment Group for the UK. ${ }^{10}$ The latter was also used by Lloyd and colleagues in their economic evaluation of etanercept in the management of chronic plaque psoriasis. ${ }^{11}$ Specifically, we simulated the use of etanercept $25 \mathrm{mg}$ twice weekly for the treatment of moderate-to-severe plaque-type psoriasis compared with nonsystemic (ie, topical) therapy. The model was run for 10 years. The key input parameters on which the model is based were obtained from three etanercept clinical trials. ${ }^{9,12,13}$ Direct costs of treating psoriasis patients, including hospitalizations and dermatology clinic visits, were taken from an Italian cost-of-illness study. ${ }^{14}$

To evaluate cost-effectiveness, the incremental cost-effectiveness ratio (ICER) was used. When the value of a new therapeutic option needs to be assessed, the ICER provides the additional resources that have to be used to achieve the additional benefit: ICER is the difference in cost $(\triangle \mathrm{C})$ divided by the difference in effect $(\triangle \mathrm{E})$ between two alternatives. In this analysis direct cost and effectiveness of intermittent etanercept were compared with direct cost and effectiveness of nonsystemic therapy.

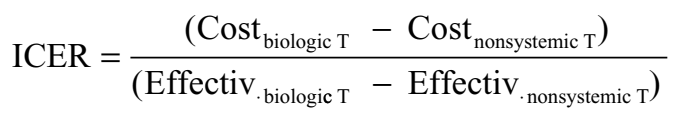

The present evaluation is a cost-utility analysis, a form of economic study in which interventions leading to different consequences in terms of quantity and quality of life are expressed as utilities (eg, a number summarizing the value patients attach to their current state of health). The qualityadjusted life-year (QALY) ${ }^{15}$ was used as utility measure and intermittent etanercept was compared with nonsystemic therapy in terms of cost per QALY. QALYs were determined based on the time trade-off (TTO) method.

\section{Structure of the model}

The Markov model is based on 12-week treatment periods spanning 10 years. After each cycle, patients pass through different categories. There is an initial phase when patients with intermittent therapy receive etanercept $25 \mathrm{mg}$ twice weekly and are then evaluated in terms of clinical response. Three events are possible:

1. Psoriasis Area and Severity Index (PASI) response $<50 \%$, considered as treatment failure $\rightarrow$ Nonresponder

2. An improvement between $50 \%$ and $74 \%$ in PASI over baseline $\rightarrow$ Partial responder

3. An improvement of at least $75 \%$ in PASI over baseline (PASI 75) $\rightarrow$ Full responder

Patients failing to achieve 50\% in PASI after a 12-week cycle (1) are classified as "treatment nonresponders," they remain in this category for the remaining time period and receive no further treatment with etanercept.

Patients experiencing an improvement between 50\% and $74 \%$ in PASI (2) are eligible for re-treatment with etanercept $25 \mathrm{mg}$ twice weekly for another 12 weeks. They are then 
re-evaluated and those reaching an improvement of PASI of least $75 \%$ are classified as "full responders" and enter the category "remission", where they temporarily suspend etanercept use. For those failing to reach this target at the end of the second cycle (24 weeks), treatment with etanercept is permanently discontinued.

Patients achieving PASI 75 after the first 12 weeks of intermittent etanercept (3) enter the category "remission". When patients in remission experience relapse (PASI worsens by $50 \%$ of the treatment effect) they are re-treated, PASI is determined again, and the patient is assigned to the new corresponding category.

Patients receiving basal treatment (ie, topical treatment only) continue on this therapy for the entire time period. Mortality was not taken into account.

A graphic description of the model is shown in Figure 1. Figure 2 illustrates the distribution of patients receiving intermittent etanercept derived from the extrapolation among the different categories over the 10-year time frame.

The model allows discounting of both costs and utilities; a discount rate of $3.5 \%$ yearly was calculated for costs and utilities in the sensitivity analyses.

Modeling was undertaken using the statistical package, Decision Data Tree (version 4.0; TreeAge Software Inc., Williamstown, MA, USA).

\section{Characteristics of the model for Italy}

Probabilities of transition were calculated based on the disease severity classes. Specifically, for patients with moderate psoriasis $(10 \leq$ PASI $<20)$, a mean PASI score of 15 was considered, whereas for patients with a severe form (PASI $\geq 20$ ), the score was approximated to 25 . By considering the clinical response to treatment and by placing that value in the appropriate response group (PASI 50, PASI 75, and PASI 90), it was possible to redistribute patients to their corresponding severity class for each time period.

Utilities were taken from a study by Zug and colleagues ${ }^{16}$ and were based on the TTO method. In the base case scenario, it was assumed that $10 \%$ of patients with moderate psoriasis and $10 \%$ of patients with severe psoriasis were treated with intermittent etanercept. As for the distribution of patients in the different severity classes, it was hypothesized that $70 \%$ were affected by mild, $20 \%$ by moderate, and $10 \%$ by severe psoriasis, in accordance with expert opinion.

\section{Costs}

Only direct costs (ie, health service costs) were considered and they were calculated from the Italian National Health Service's perspective. Regarding nonsystemic standard of care, costs varied from $€ 305$ to $€ 7,960$ per patient per year depending on the severity of psoriasis and they comprised expenditure for a) hospitalization; b) day-hospital admissions; c) specialist medical examinations; d) laboratory tests and instrumental investigations; e) phototherapy; or f) drug therapies. Expenses for items a) and b) were evaluated based on the national diagnosis-related group (DRG) system available from the Italian Ministry of Health, whereas items c) to f) were obtained from the "2006 National Tariff Nomenclator." ${ }^{14}$

Treatment with intermittent etanercept entailed the cost of the drug, the fees for the physician and other medical staff. The price of etanercept is $€ 4,788$ per cycle, considering the dosage chosen ( $25 \mathrm{mg}$ twice weekly). To evaluate medical staff time, it was assumed that $10 \%$ of patients received home visits for etanercept injections. ${ }^{17}$ It was calculated that each visit lasted 15 minutes on average for a total annual cost of

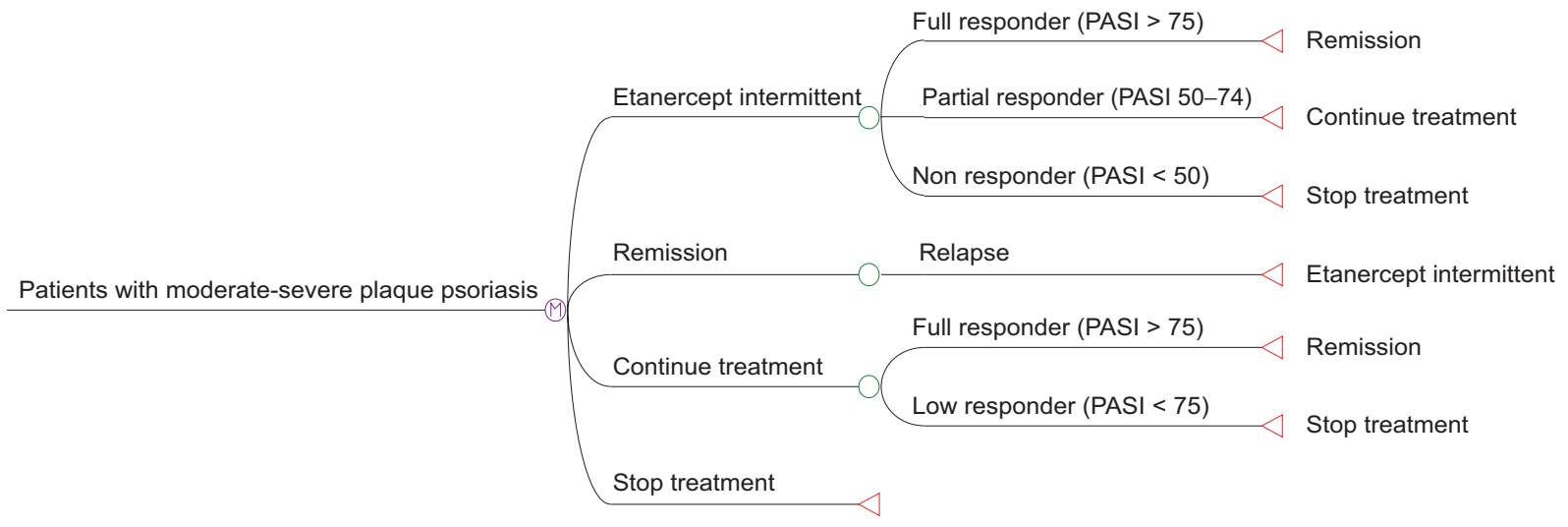

Figure I Model structure.

Abbreviation: PASI, Psoriasis Area and Severity Index. 


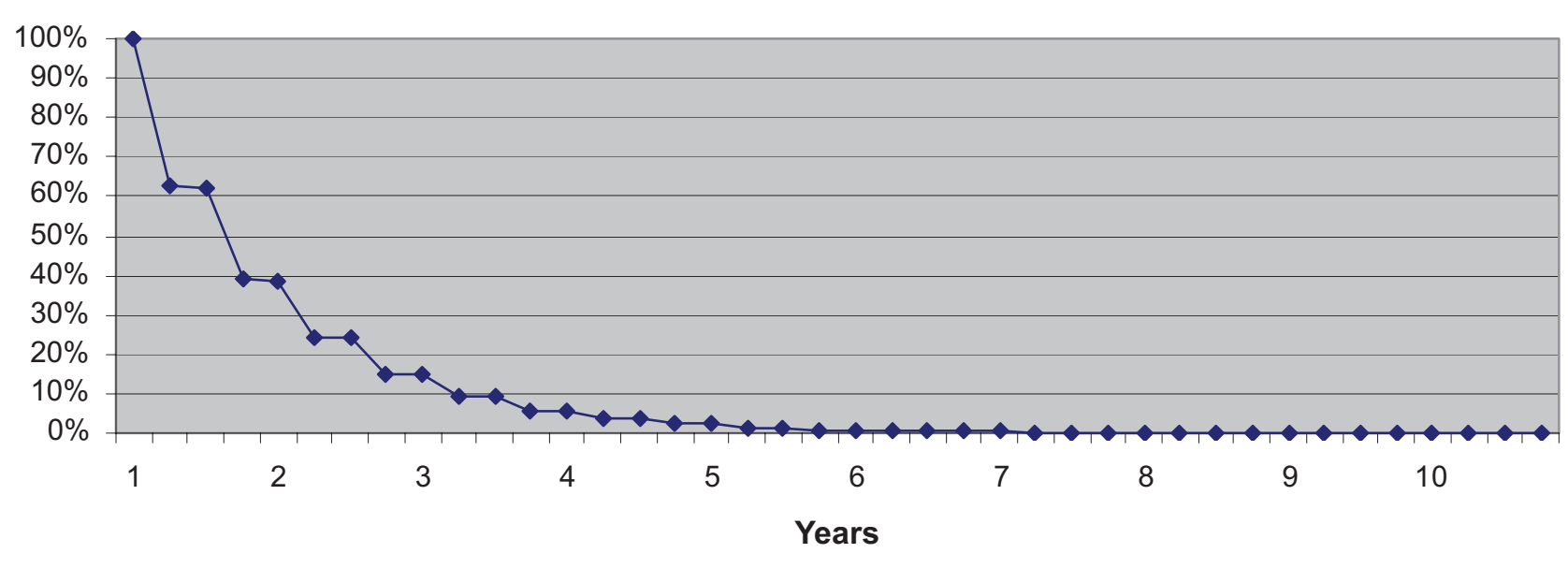

Treatment

Figure 2 Percent of patients initiated on intermittent treatment with etanercept who remain on etanercept by year.

$€ 58.42$ per patients. Hence, total annual costs of treatment with etanercept are $€ 9,725$. Costs for side effects were not included into the model but were taken into consideration in the sensitivity analyses. All costs are expressed in euros and are updated to 2008 values according to the official inflation rates. ${ }^{18}$

\section{Results}

The results of our extrapolations show that treatment cost of moderate-to-severe plaque-type psoriasis with intermittent etanercept ( $25 \mathrm{mg}$ twice weekly) during the first year of treatment is nearly twice that of nonsystemic standard of care (€8,528 vs $€ 3,693)$; this amount is halved during the second year of therapy and tends to decrease constantly as a result of treatment discontinuation. Expenses for nonsystemic standard of care diminish slightly during the first year and then remain constant for the remaining nine years (Figure 3). Costs for treating psoriasis are very sensitive to the severity of disease. To obtain some insights on the average direct costs per individual over the 10 -year time window, we stratified our patient population into two groups with different baseline severity: patients with moderate and severe psoriasis (PASI $\geq 10$ ) and patients with severe psoriasis (PASI $\geq 20$ ).

The results are reported in Table 1 and show that the average total direct costs per patient with an initial PASI score of 20 or higher treated with etanercept is $€ 55,959$ over 10 years, compared with $€ 40,051$ of patients with PASI of 10 or higher. This relationship holds also in the case of

\section{Direct costs}

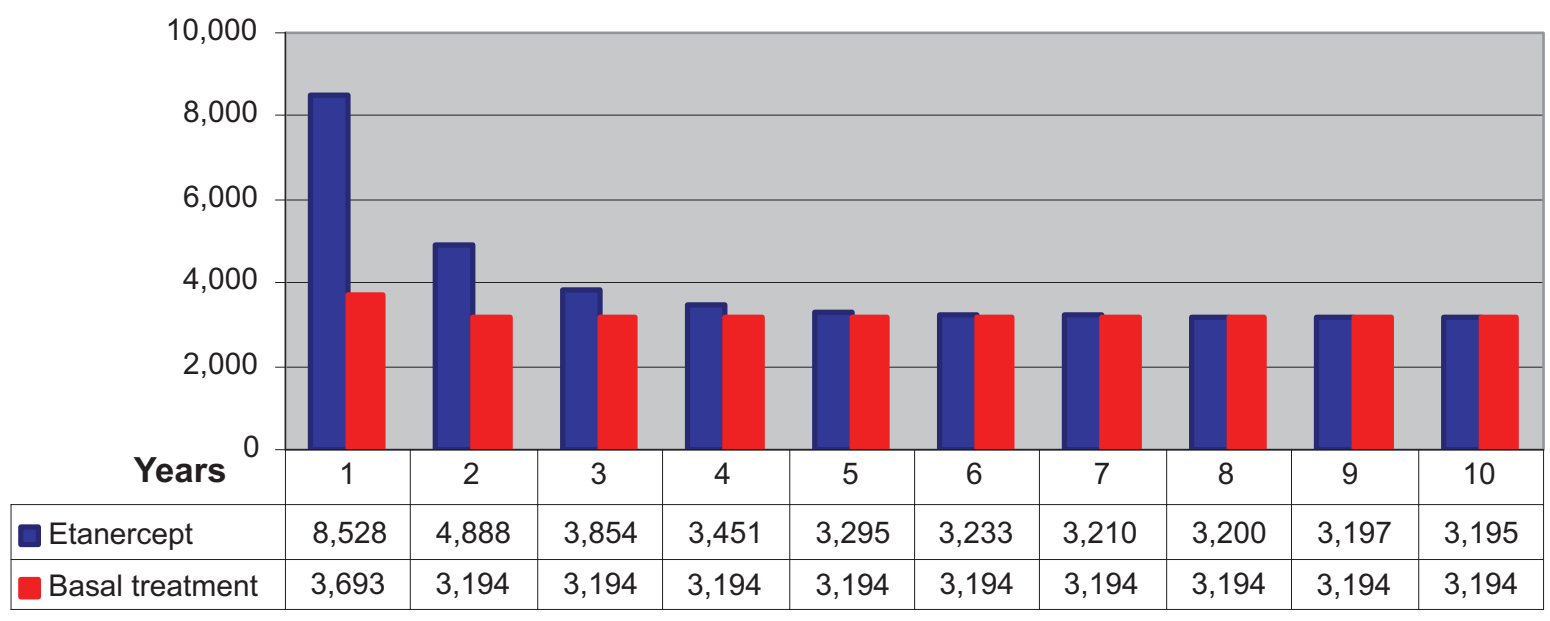

Figure 3 Direct costs of etanercept and basal treatment. 
Table I Results for different degrees of initial disease severity

\begin{tabular}{lllll}
\hline & $\begin{array}{l}\text { Initial PASI } \\
\text { score }\end{array}$ & $\begin{array}{l}\text { Average total cost per patient } \\
\text { in EUR (over 10 years) }\end{array}$ & $\begin{array}{l}\text { Average QALYs per } \\
\text { patient (over 10 years) }\end{array}$ & $\begin{array}{l}\text { ICER (Incremental Cost } \\
\text { Effectiveness Ratio) }\end{array}$ \\
\hline Etanercept & $\geq 10$ & $€ 40,05 I$ & 6,778 & $€ 33,216$ \\
Basal treatment & & $€ 32,441$ & 6,549 & \\
Etanercept & $\geq 20$ & $€ 55,959$ & 6,332 & $€ 25,486$ \\
Basal treatment & & $€ 50,045$ & 6,100 & \\
\hline
\end{tabular}

Abbreviation: ICER, incremental cost-effectiveness ratio; QALY, quality-adjusted life-year; PASI, psoriasis area and severity index.

nonsystemic therapy where expenses are higher with more severe forms of the disease: $€ 50,045$ and $€ 32,441$ over 10 years, respectively (Table 1).

When ICER is considered, the situation is reversed in that for patients receiving intermittent therapy with etanercept, the additional cost per QALY gained is lower for individuals affected by severe (PASI $\geq 20$ ) psoriasis $(€ 25,486)$ compared with individuals with a moderate-andsevere form (PASI $\geq 10)$ of the disease $(€ 33,216)$ (Table 1$)$. Etanercept was more cost-effective in the patients with more severe disease, partly due to greater cost offsets and partly due to a greater improvement from baseline in utility, than it was in the patients with more moderate disease.

\section{Sensitivity analysis}

To test the robustness of the analysis, sensitivity analyses were carried out by varying some parameters, namely the cost of hospitalization, efficacy and the discounting rate. By increasing the cost of etanercept by $20 \%$, patients would obtain ICERs of $€ 42,216 / \mathrm{QALY}$ (PASI $\geq 10$ ) and $€ 33,968 /$ QALY (PASI $\geq 20$ ). Conversely, if the cost of the biologic were decreased by $20 \%$, ICERs for patients with PASI of 10 or higher and with PASI of 20 or higher would be $€ 24,216 /$ QALY and $€ 17,004 / \mathrm{Q} A L Y$ respectively. As expected, ICERs are higher or lower compared with the base case scenario, but in both cases the lower relative cost per QALY of etanercept is associated with more severe forms of plaque-type psoriasis, thus confirming the results obtained in the primary analysis. When all other costs are either increased or decreased by
$20 \%$, ICERs do not differ significantly from the values obtained in the base case, in both groups of disease severity. This result may be due to patients in both etanercept and nonsystemic standard of care groups confronting many of these same costs. A similar result occurs when a single cost such as hospitalization is varied by $20 \%$. All sensitivity results are shown in Tables 2 and 3 and in Figure 4.

Table 3 presents results in sensitivity analysis when an upper and lower estimate of $20 \%$ difference from the primary analysis for efficacy is used in both treatment options and in discounting. Such changes moved the ICER by $3 \%$ to $12 \%$.

\section{Discussion}

We analyzed the cost-utility of etanercept, one of the biological therapies licensed in Italy for the treatment of moderate-to-severe plaque-type psoriasis in adults who failed to respond to, or who have a contraindication to, or are intolerant to other systemic therapy. The analysis was based on a Markov model that allowed us to make long-term extrapolations over a 10 -year time horizon. Initially, direct costs associated with intermittent etanercept are significantly higher compared with nonsystemic standard of care, then they decrease progressively for two main reasons. First of all, some patients discontinue etanercept in line with the model's assumptions on efficacy, as described in the section on Materials and methods. Secondly, due to etanercept's greater efficacy, patients remain in less severe severity classes compared with subjects receiving nonsystemic standard of care, thus producing clinical and economical advantages.

Table 2 Sensitivity analysis on costs

\begin{tabular}{|c|c|c|c|c|c|c|c|}
\hline & \multirow[b]{2}{*}{$\begin{array}{l}\text { Initial PASI } \\
\text { score }\end{array}$} & \multirow[b]{2}{*}{$\begin{array}{l}\text { Etanercept } \\
\text { cost }+20 \%\end{array}$} & \multirow[b]{2}{*}{$\begin{array}{l}\text { Etanercept } \\
\text { cost }-20 \%\end{array}$} & \multicolumn{4}{|c|}{ ICER (Incremental Cost Effectiveness Ratio) } \\
\hline & & & & $\begin{array}{l}\text { Basal treatment } \\
\text { cost }+20 \%\end{array}$ & $\begin{array}{l}\text { Basal treatment } \\
\text { cost }-20 \%\end{array}$ & $\begin{array}{l}\text { Hospitalization } \\
\text { cost }+20 \%\end{array}$ & $\begin{array}{l}\text { Hospitalization } \\
\text { cost }-20 \%\end{array}$ \\
\hline $\begin{array}{l}\text { Etanercept } \\
\text { Basal treatment }\end{array}$ & $\geq 10$ & $€ 42,216$ & $€ 24,216$ & $€ 32,224$ & $€ 34,208$ & $€ 32,384$ & $€ 34,048$ \\
\hline $\begin{array}{l}\text { Etanercept } \\
\text { Basal treatment }\end{array}$ & $\geq 20$ & $€ 33,968$ & $€ 17,004$ & $€ 24,211$ & $€ 26,761$ & $€ 24,175$ & $€ 26,797$ \\
\hline
\end{tabular}

Abbreviation: ICER, incremental cost-effectiveness ratio. 
Table 3 Sensitivity analysis on efficacy

\begin{tabular}{lllllll}
\hline & & \multicolumn{2}{l}{ ICER (Incremental Cost Effectiveness Ratio) } & \\
\cline { 3 - 7 } & $\begin{array}{l}\text { Initial PASI } \\
\text { score }\end{array}$ & $\begin{array}{l}\text { Etanercept } \\
\text { efficacy }+20 \%\end{array}$ & $\begin{array}{l}\text { Etanercept } \\
\text { efficacy 20\% }\end{array}$ & $\begin{array}{l}\text { Basal treatment } \\
\text { efficacy }+20 \%\end{array}$ & $\begin{array}{l}\text { Basal treatment } \\
\text { efficacy -20\% }\end{array}$ & $\begin{array}{l}\text { Discounting } \\
\text { rate 3,5\% }\end{array}$ \\
\hline Etanercept/Basal treatment & $\geq 10$ & $€ 35.931$ & $€ 29.277$ & $€ 34.017$ & $€ 32.440$ & $€ 33.192$ \\
Etanercept/Basal treatment & $\geq 20$ & $€ 26.235$ & $€ 23.670$ & $€ 26.200$ & $€ 24.791$ & $€ 25.537$ \\
\hline
\end{tabular}

Abbreviation: ICER, incremental cost-effectiveness ratio.

By stratifying the patient population into two groups, namely with moderate and severe plaque psoriasis $($ PASI $\geq 10)$ and severe plaque psoriasis (PASI $\geq 20$ ), we obtained cost-effectiveness ratios of $€ 33,216$ and $€$ 25,486 , respectively. It is worth noting that incremental cost-effectiveness versus standard of care is lower with more severe forms of the disease and this result is in line with literature data. This relationship was also confirmed in sensitivity analyses where costs and efficacy were varied.

Our economic evaluation has some limitations. First of all, it is important to observe that this analysis is limited by the data available: literature data, such as efficacy, entered into the model are based on a short-term time-frame (about 24 months) which may be inadequate for modeling the treatment of a chronic disease for a longer time-horizon. Secondly, utility data were derived from the TTO questionnaires obtained from an American survey ${ }^{16}$ on patients with psoriasis, assuming that health state preferences would be similar for the Italian setting. Thirdly, costs related to possible adverse effects were not entered into the model but were only considered when sensitivity analyses were performed and costs were varied. The hypothesis was that their impact would be relatively small but this may have led to underestimation of costs especially for more severe cases, where the number of hospitalizations increases. Neither was mortality considered, based on the assumption that although it can have a major negative effect on QALYs, life span is generally not thought to be affected. ${ }^{1}$

To conclude, our aim was to create a health economic model to investigate the potential economic effect of intermittent etanercept compared with topical treatment, considering that licensed biological treatments provide a major advance in the treatment of plaque psoriasis though their use is currently restricted.

As for Italy, this is to our knowledge the first attempt to undertake a cost-utility analysis. Despite the limits of this kind of evaluation, we were able to show that the incremental costs per QALY gained for patients receiving intermittent

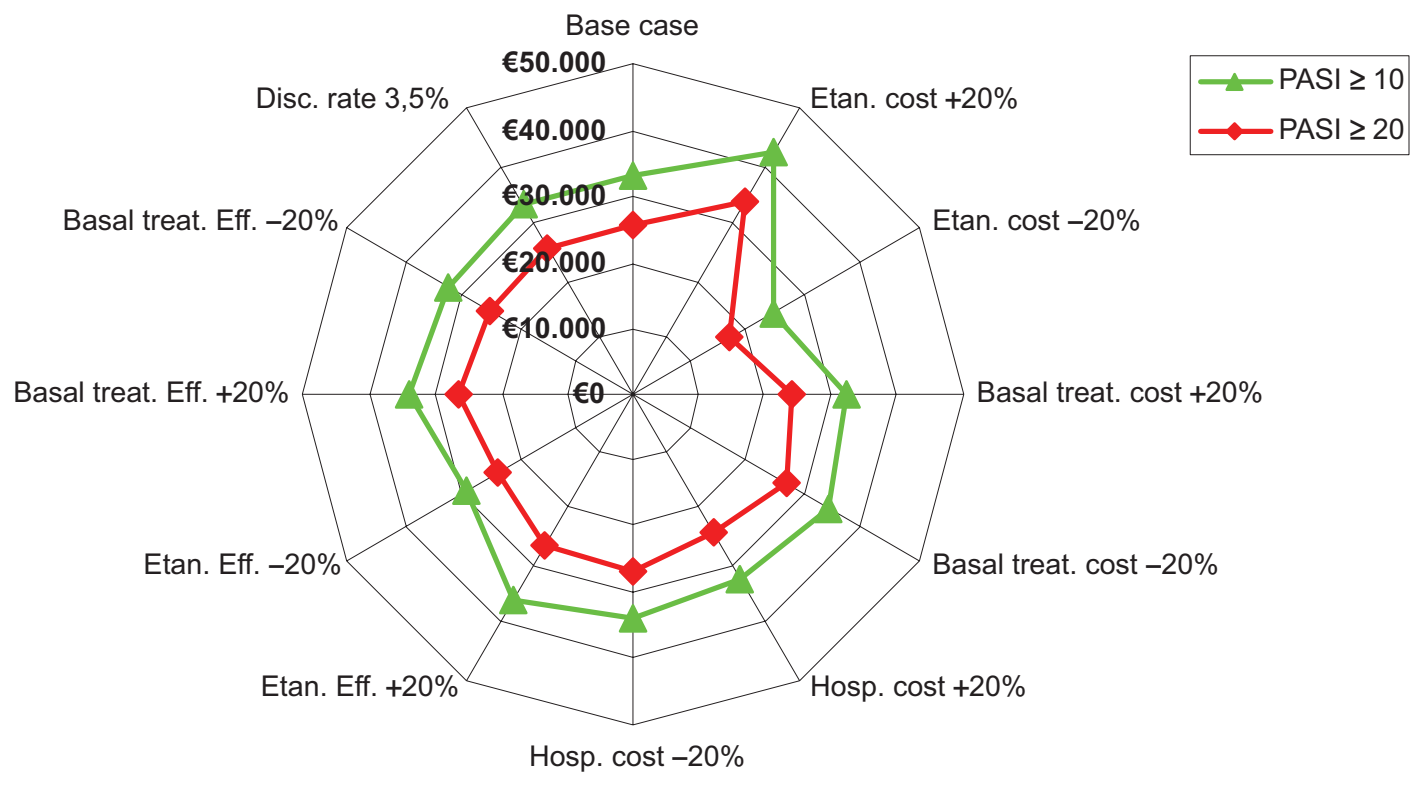

Figure 4 Findings of sensitivity analysis: cost per QALY gained.

Abbreviations: QALY, quality-adjusted life-year; PASI, psoriasis area and severity index. 
etanercept were lower in cases with worse baseline quality of life and clinical severity. Though no officially established threshold on cost per QALY is available for Italy, our results ( $€ 25,486 /$ QALY and $€ 33,216 /$ QALY for etanercept) are lower than two commonly accepted thresholds of $€ 36,500 /$ QALY $^{19}$ and $€ 60.000 /$ QALY $^{20}$ calculated by two different authors for the Italian setting.

\section{Disclosure}

The study was financially supported by Wyeth Lederle, Aprilia, Italy.

\section{Acknowledgments}

The authors would like to thank Sara Ratti (S.A.V.E. Studi Analisi Valutazioni Economiche, Milan Italy) for editorial assistance.

\section{References}

1. Lebwohl M. Psoriasis. Lancet. 2003;361(9364):1197-1204.

2. Smith $\mathrm{CH}$, Barker JN. Psoriasis and its management. BMJ. 2006;333(7564):380-384.

3. Smith $\mathrm{CH}$, Anstey AV, Barker JN, et al. For British Association of Dermatologists. British Association of Dermatologists guidelines for use of biological interventions in psoriasis 2005. Br J Dermatol. 2005; 153(3):486-497.

4. Thaçi D. Long-term data in the treatment of psoriasis. Br J Dermatol. 2008;159(Suppl 2):18-24.

5. Gottlieb AB, Chao C, Dann F. Psoriasis comorbidities. J Dermatolog Treat. 2008;19(1):5-21.

6. European Medicines Agency. Annex 1: Summary of product characteristics (Enbrel). Available from: http://www.emea.europa.eu/ humandocs/PDFs/EPAR/Enbrel/emea-combined-h262en.pdf. Accessed on September 10, 2009.

7. European Medicines Agency. Annex 1: Summary of product characteristics (Remicade). Available from: http://www.emea.europa. eu/humandocs/PDFs/EPAR/Remicade/emea-combined-h240en.pdf Accessed on September 10, 2009.
8. European Medicines Agency. Annex 1: Summary of product characteristics (Humira). Available from: http://www.emea.europa.eu/ humandocs/PDFs/EPAR/humira/emea-combined-h481en.pdf. Accessed on September 10, 2009.

9. Papp KA, Tyring S, Lahfa M, et al; for Etanercept Psoriasis Study Group. A global phase III randomized controlled trial of etanercept in psoriasis: safety, efficacy, and effect of dose reduction. Br J Dermatol. 2005;152(6):1304-1312.

10. Woolacott N, Hawkins N, Mason A, et al. Etanercept and efalizumab for the treatment of psoriasis: a systematic review. Health Technol Assess. 2006;10(46):1-233, i-iv.

11. Lloyd A, Reeves P, Conway P, Reynolds A, Baxter G. Economic evaluation of etanercept in the management of chronic plaque psoriasis Br J Dermatol. 2009;160(2):380-386.

12. Gottlieb AB, Matheson RT, Lowe N, et al. A randomized trial of etanercept as monotherapy for psoriasis. Arch Dermatol. 2003;139(12):1627-1632.

13. Leonardi CL, Powers JL, Matheson RT, et al; Etanercept Psoriasis Study Group. Etanercept as monotherapy in patients with psoriasis. New Eng J Med. 2003;349 (21):2014-2022.

14. Colombo GL, Altomare GF. Moderate and severe plaque psoriasis: cost-of-illness study in Italy. Ther Clin Risk Manag. 2008;4(2): 559-568.

15. Drummond MF, O’Brien B, Stoddart GL, Torrance GW. Methods for the Economic Evaluation of Health Care Programmes. 2nd ed. New York, NY: Oxford; 1987: p. 165.

16. Zug KA, Littenberg B, Baughman RD, et al. Assessing the preferences of patients with psoriasis. A quantitative, utility approach. Arch Dermatol. 1995;131(5):561-568.

17. Colombo GL, Muzio A, Longhi A. Valutazione economica di Infliximab $\left(\right.$ Remicade $^{\circledR}$ ) vs Etanercept $\left(\right.$ Enbrel $\left.^{\circledR}\right)$ nel trattamento dell'artrite reumatoide. Farmeconomia e percorsi terapeutici. 2003;4(2): 189-198.

18. National Institute of Statistics. Italian inflation rates. Available from: http://www.istat.it/prezzi/precon/rivalutazioni. 2008. Accessed February 12, 2009.

19. Lucioni C, Ravasio R. Come valutare i risultati di uno studio farmacoeconomico? PharmacoEconomics - Italian Research Articles. 2004;(3):121-130.

20. Messori A, Santarlasci B, Trippoli S, Vaiani M. Controvalore economico del farmaco e beneficio clinico: Stato dell'arte della metodologia e applicazione di un algoritmo farmacoeconomico. Pharmaco Economics - Italian Research Articles. 2003;5:53-67.
ClinicoEconomics and Outcomes Research

\section{Publish your work in this journal}

ClinicoEconomics \& Outcomes Research is an international, peerreviewed open-access journal focusing on Health Technology Assessment, Pharmacoeconomics and Outcomes Research in the areas of diagnosis, medical devices, and clinical, surgical and pharmacological intervention. The economic impact of health policy and health systems

\section{Dovepress}

organization also constitute important areas of coverage. The manuscript management system is completely online and includes a very quick and fair peer-review system, which is all easy to use. Visit http://www.dovepress.com/testimonials.php to read real quotes from published authors. 